\title{
Reading in the (post)digital age: \\ Large databases and the future of literature in secondary English classrooms
}

\author{
Larissa McLean Davies, Katherine Bode, Susan K. Martin and Wayne Sawyer
}

\begin{abstract}
While "born digital" artefacts such as video games and works of e-literature have been part of secondary school English in Anglophone countries for more than two decades (Beavis, 1998; Durrant \& Beavis, 2001; Gee, 2003; Buckingham \& Burn, 2007; Cowdy, 2016; O’Mara, 2019), databases of mass-digitised (and hence "re-mediated") literary texts are yet to have a significant presence in, or influence on, literary work in subject English. The authors contend that engagement with these digitised texts requires us to enact a postdigital (Ablitt 2019) 'literary literacy' (Green 2006).

The authors explore how "distant reading" (Moretti 2013), which involves applying digital tools to large-scale data to identify patterns beyond the scale of human perception, offers a form of postdigital literary literacy that can be enacted alongside others, including productive reading and code switching. Using the example of the To be continued database of fiction originally published in 19th and early 20th century Australian newspapers, the article argues that postdigital literary objects offer new possibilities for literary knowledge and new ways of thinking about the purpose and role of literary study and teacher expertise in English in the $21^{\text {st }}$ century.
\end{abstract}

\section{Part 1: Teaching literature and the changing nature of teacher expertise in subject English}

Reading literature is central to subject English as it is taught in Anglophone countries. As Nancy Glazener observes, literature is

identified as a measure of excellence ... made an index of the health and strength of a people; credited with fostering modes of public reflection crucial to civil society; entrusted with values and forms of experience believed to be at risk in modern life; and held to play a special role in readers' intellectual, moral, and emotional development. $(2015,4-5)$

Those who decide to become English teachers often do so because of their own experience with, and belief in the value of, reading literature (Goodwyn 2012; Manuel \& Carter 2016), along with their institutional success as readers. From the earliest days of the formal teaching of the subject, expertise in reading and selecting literature has been considered essential for English teachers: a mark of their capacity and, indeed, of their quality. An analysis of major UK curriculum documents on subject English since the 1920s shows that being 'well read' across a substantive body of canonical literature, has long been a key expectation of English teachers (McLean Davies \& Sawyer, 2020). This expectation remains key for contemporary teachers in the UK and Australia and can present significant challenges given the expansive nature of the subject, parental expectations, and the culture of high-stakes assessment, especially at upper secondary levels (McLean Davies \& Sawyer 2020; McLean Davies et al forthcoming).

While literature continues to hold a prime place in this curriculum area, the history of subject English shows that what it means to be "well read" as well as what constitutes a literary text have not remained static. In Australia, where the authors based, it is no longer assumed that literary study in subject English refers exclusively to print texts, although these continue to endure in this country as around the world (Beavis 2013). Australian scholars have been at the forefront of the multiliteracies movement, and this has strongly influenced the way in which literary studies are conceived (Beavis 1998; Cope \& Kalantzis 2000; Mills 2016). Film, graphic novels, video games and other multimodal texts have become core to secondary English and have expanded the traditional definition of "literature". This shift reflects the changing nature of students' textual practices since the late 20th century, and the increased value placed on multimodal forms both for artistic and aesthetic creation and for communication in contemporary societies. By identifying Literature as one of the core strands of the curriculum (along with Language and Literacy), the Australian Curriculum: English (AC:E) both affirms the core role of Literature in subject English, and defines this category in expanded terms including with respect to multimodal texts and diverse genres:

Literature includes a broad range of forms such as novels, poetry, short stories and plays; fiction for young adults and children, multimodal texts such as film, and a variety of non-fiction. Literary texts also include excerpts from longer texts (ACARA 2016) 
The impact of the multimodal or digital turn in subject English has led to a substantial rethinking of what constitutes pedagogical content knowledge (Shulman 1986) and the role of literacy across the curriculum (Christie \& Derewianka 2008). For teachers, this change in the contents and materials of subject English - and in the redefinition of key categories such as "literature"- has led to the development of new subject-matter expertise and the adoption of pedagogical frameworks that include "digital literacies" (Lankshear \& Knobel, 2008). Now central to secondary English are ways of reading and teaching reading that had not been imagined when many current teachers were in secondary school or preparing to become teachers. The changing nature of expertise in this subject area is reflected in text books and publications for pre-service English teachers, which increasingly extend the notion of the literary and attend to a range of multimodal texts and associated reading practices (McCallum, 2012; Doecke et al, 2014, Sawyer, 2019). The ability of English teachers to adapt to and embrace new types of texts and critical reading paradigms highlights both the fluid and malleable nature of subject English (Durrant 2004) and the cumulative, unbounded and agile quality of teacher expertise in this curriculum area.

Teacher expertise has traditionally been discussed in terms of parameters such as content knowledge and capabilities in pedagogy, particularly in a specific discipline or grade level (eg Robinson, 2009; DarlingHammond, 2000, 2007; Darling-Hammond \& Bransford, 2005; Goe, 2007; Zammit et al. 2007), dimensions that were famously brought together by Shulman (1986). Goodwyn and Enow have repurposed frameworks for the development of expertise specifically for English teaching from Hattie and Dreyfus (Goodwyn, 2010; Enow \& Goodwyn, 2018). While affirming these understandings, we foreground the importance of a willingness and agility in responding to changes in the form of literature as a key component of expertise in subject English. Literary forms are always evolving, but the digital age is producing the most significant technological developments in literary culture since the print revolution, such as literary databases and massdigitised texts. In this new technological context, the capacity of English teachers to adapt to new textual forms is especially important. Such responsiveness as a factor in teacher expertise has rarely been better demonstrated than in the worldwide "re-siting" of classrooms necessitated by COVID-19.

Following literary critic Stephen Abblitt (2019) we adopt the term "postdigital literary objects" to describe prominent literary databases and mass-digitised texts. Abblitt uses this phrase to emphasise how associations naturalised by printed texts no longer pertain to textuality and its pedagogy in the digital age. Drawing on Hayles (2004) and others, he describes the postdigital literary object as a process: it exists as "a complex set of semiotic and socio-material human and non-human networks and relationships of production, circulation, and consumption" (102). Accordingly, postdigital literature is not limited to texts in the traditional sense, for instance, novels or short stories created by individual authors; nor is it only extended to what we might call the "surface" of born-digital works, such as the images presented on video games or the interactive interfaces of e-literature. Rather, it should be understood as emergent processes that might include the software and code that perform these born-digital works as well as the digitisation and search algorithms and databases that increasingly organise literary culture. Abblitt is clear that the postdigital age changes "the nature of the literary object we study and the human subject we teach," and has major "implications ... for the future of literary pedagogy" (105). We argue, drawing on Abblitt, that as the form of literature and what it means to encounter it evolves, so too must subject English. Where Ablitt offers no specific indications of how these changes might be enacted, though, we demonstrate a framework for subject English that could facilitate this development based on the concept of postdigital literary literacies.

In the next section, we discuss the engagement of digital humanities with postdigital literary objects, especially databases, before introducing the literate practices and modes of expertise that are useful for "reading" them in the secondary English classroom. In the paper's final section, we offer examples of how these approaches, which would be suitable for years 9 and above, might be used in secondary school contexts, and what this might mean for teacher expertise and approaches to literary pedagogy. While engaging effectively with postdigital literary objects requires the development of new knowledge, skills and expertise, we see this development as consistent with the evolving nature of subject English, as a compulsory study. Further we see these expansions to the scope and scale of literature in English as part of the role that English teachers play (Goodson and Medway 1990), in each generation, of reappraising and expanding what constitutes both literary study and engaged and empowered reading for students.

\section{Part 2: A brief history of digital humanities and digital literary reading practices in education}

Computers have been used in tertiary literary studies since at least the 1960s. Yet in the last two decades they have become increasingly prominent, leading to the development of a field of study called digital humanities. 
For literary studies, a key feature of this development has been the creation of very large databases of remediated or digitised literary texts. Most prominent among these are mass-digitised libraries, such as Google Books, HathiTrust, the Internet Archive, Project Gutenberg, and Europeana, as well as more nationally-oriented projects such as the Bibliotheque nationale de France's Gallica and the National Library of Australia's Trove. There are also digital archives which focus on works by particular authors (e.g. The Rossetti Archive [McGann nd]), particular groups of authors (e.g. the Women Writers Project [Flanders nd]), particular genres (Emory Yellowbacks [Dunne et al]) or particular historical periods (e.g. Perseus Digital Library of ancient Greek and Latin texts [Crane]). These collections of digitised literary works not only give unprecedented access to a huge range of historical literature, but also expand the nature of the literary object: individual works are now, very clearly or materially, parts of intersecting and interconnected systems of texts.

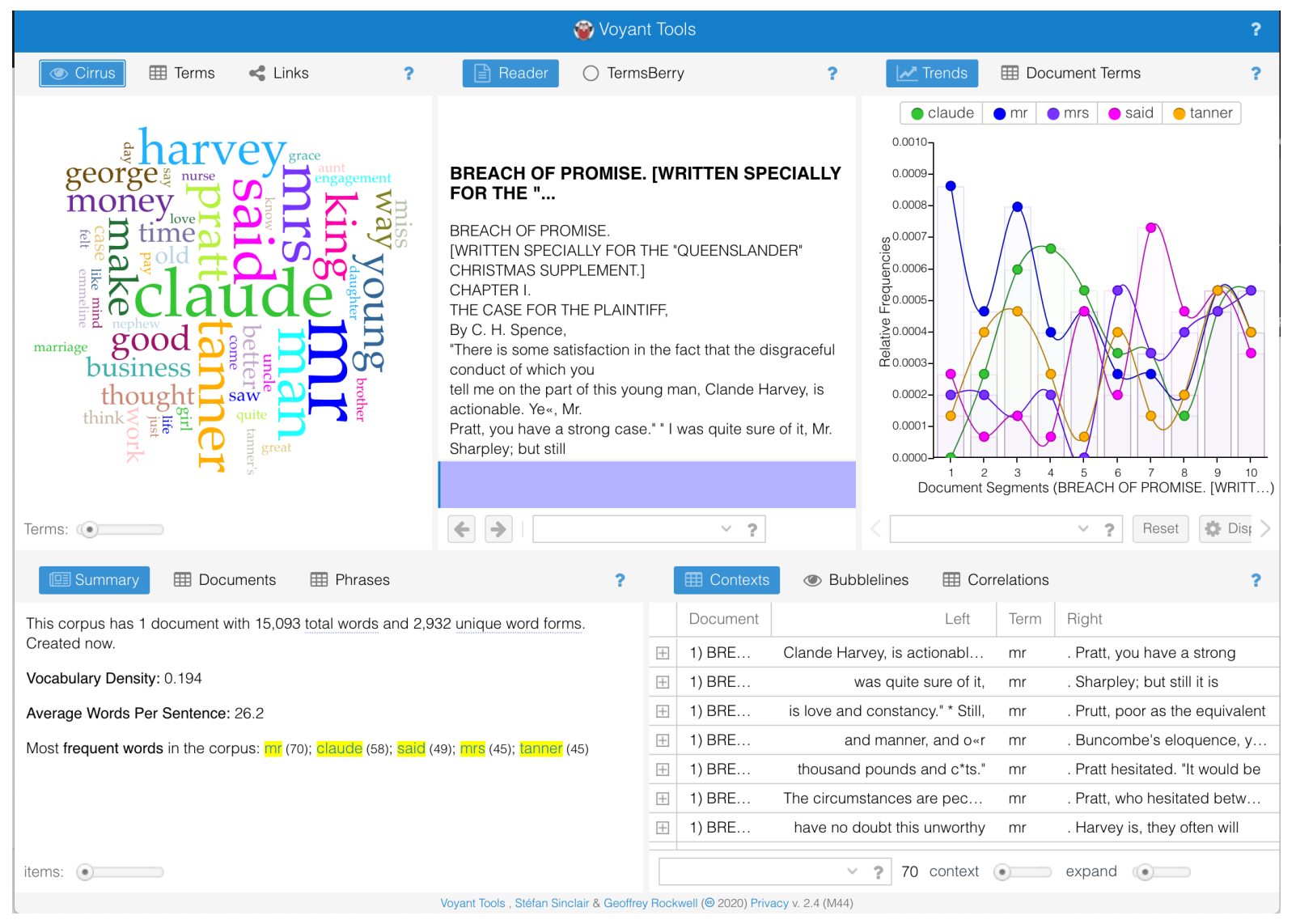

Fig 1. Voyant initial analysis of Spence 'Breach of Promise' using text from To be continued https://voyanttools.org

Another prominent feature of digital humanities has been the creation or adaptation of open-access digital tools for analysing these extensive text collections. Some require the use of computer languages such as Python or software environments such as $R$. Many tools, though, are available in relatively accessible formats with GUIs (Graphic User Interfaces) existing for geospatial analysis (Palladio), network modeling (Cytoscape), text analysis (Voyant, see Figure 1) and machine learning techniques such as topic modeling (such as $j s L D A$, an interface which we will discuss in detail shortly). Applying these techniques to large collections or databases of digitised texts is often referred to as "distant reading", a term coined by Franco Moretti in 2000 and developed extensively in two subsequent books: Graphs, Maps, Trees (2005) and Distant Reading (2013). Other terms used to describe this work with digital tools include "cultural analytics" (Manovich 2016), "macroanalysis" (Jockers 2013) and "computational literary studies" (Da 2019). As Moretti (2000) explained in introducing "distant reading," the intention is "to focus on units that are much smaller or much larger than the text: devices, themes, tropes - or genres and systems" (57). While databases can be understood as new textual (spatial, statistical, visual) artefacts, the outputs of digital tools applied to these databases also create new texts, combining statistical, textual, and visual modes in the form of models, that can be used for analysis. 
These approaches have attracted considerable controversy in tertiary literary studies (e.g. Da 2019). In large part, the negative perception is a response to the original, polemical proclamations that scholars such as Moretti made on behalf of these methods, including his contention that "distant reading" should replace "close reading" or the detailed textual analysis of individual literary works (e.g. Moretti 2005). It is also true that, in some digital humanities approaches, applying computational tools to large text databases is taken to comprise the analysis in its entirety, with the results simply needing to be reported. Unlike Moretti, we see close reading practices as remaining central to literary studies and secondary English education and argue that they can be combined with "distant reading" methods. Our approach, in other words, sees both "close" and "distant" reading as part of a spectrum of literacy practices pertinent to literary investigation and exploration in the postdigital age. While the tools and databases of the digital humanities might seem entirely different from what has come before them, we contend that they maintain the aspects of literature that have underpinned its centrality in secondary English education, including how it helps us to understand more about ourselves, the world and the way we create meaning in it. Engaging in this digitised environment, though, necessitates a broadening of expertise and literate practices.

Following Ablitt's (2019) definition (above) of the postdigital we use the concept of "postdigital literary literacies" as an enabling framework for thinking through an expanded repertoire of practices available to literary study in the $21^{\text {st }}$ century and outline three forms these literate practices might take: "productive reading," "distant reading" and "code switching." These terms come with considerable histories, and we use them here to emphasise that what we are proposing is a continuation of the ongoing development of literacy and literature over time. Drawing on Foucault, "productive reading" has been used to describe rich reading practices, conducted with individual texts, and interested in generating new concepts and perspectives rather than reproducing an existing set of ideas (Muckelbauer, 2000). We extend this description to consider how a wide range of activities with postdigital literary objects - for instance, selecting, recombining, curating and remixing - constitute the production of meaning in classrooms. As noted above, while "distant reading" is sometimes taken to describe digital humanities approaches to literature in their entirety, we use it to mean the production and investigation of a new type of postdigital literary object: namely, a model. Finally, while "code switching" is a linguistic term, referring to movement between languages (Bullock \& Toribio, 2009), we use it to support the idea that one of the ways to arrive at literary meaning in the postdigital environment is by moving between models and the individual literary works to which they refer.

We see these postdigital literary literacies as an expansion of Bill Green's concept of a "literary literacy" (Green 2002). Green articulates "literary literacy" partly in terms of action and process, concerning "doing things with texts" $(2008,16)$. His conceptualisation contests the long-standing bifurcation of literary learning and literacy by identifying the literacy project of English teaching as located in the poetic and the imaginary, in metaphor and narrative, and as concerned with creativity and semantic innovation (Green, 2002). By considering this concept in terms of postdigital literary objects, we propose ways of working with texts that expand the types of literacy practices and literary knowledges relevant to secondary English in the 21 st century.

\section{Part 3: Thinking through the possibilities of a postdigital literary literacy in the English classroom}

To explore how postdigital literary literacies might be enacted by teachers and students in English classrooms, we turn now to the example of a large text database and a particular digital tool. The database is To be continued: The Australian Newspaper Fiction Database (Bode and Hetherington 2018), which is publicly available and based on the National Library of Australia's open-access database of digitised historical newspapers. The database holds over 23,000 publications of novels, novellas and short stories, literary and popular, from around the world (Australia, Britain and America, especially, but also Austria, Canada, France, Germany, and many more). Since it was publicly launched in March 2018 it has attracted a crowdsourcing community who have corrected Optical Character Recognition errors in the text of thousands of stories and added over 2,000 new publications.

\section{Productive reading}

We suggest that to read the database and the digitised texts it makes available productively, readers need to ask questions about how this postdigital literary object was constituted. Whereas, in approaching a printed literary text, the reader might ask a question about genre - is this a poem, or a graphic novel, a short story, or a noir film? - a postdigital "productive reading" extends the questions relevant to understanding the creation 
of literature to a wider range of issues - formal, material, historical, and technical - than are typically asked when students encounter printed texts. The point is not to reject aesthetic meaning, but rather to explore how the production of literary texts as, for instance, national or canonical artefacts, involves an amalgam of processes that extend well beyond the artistic or literary historical. Answering those questions requires productive and processual - rather than what we might call critical or rhetorical - practices, involving selecting, reorganising, composing and remixing the postdigital literary object. The results of these procedures do not reveal, but create the possibilities of, the literary meanings students can gain. In arguing this, we acknowledge that media studies in England, and subject English in Australia have, since the 1990s, included a greater attention to text history and the ways in which production decisions, particularly with regard to technology, impact on the way in which we make meaning with texts. The productive reading practices we discuss below draw on this practice of attending to language and semiotic systems but extend this to consider how these practices might be deployed across a massive corpus of digitised texts.

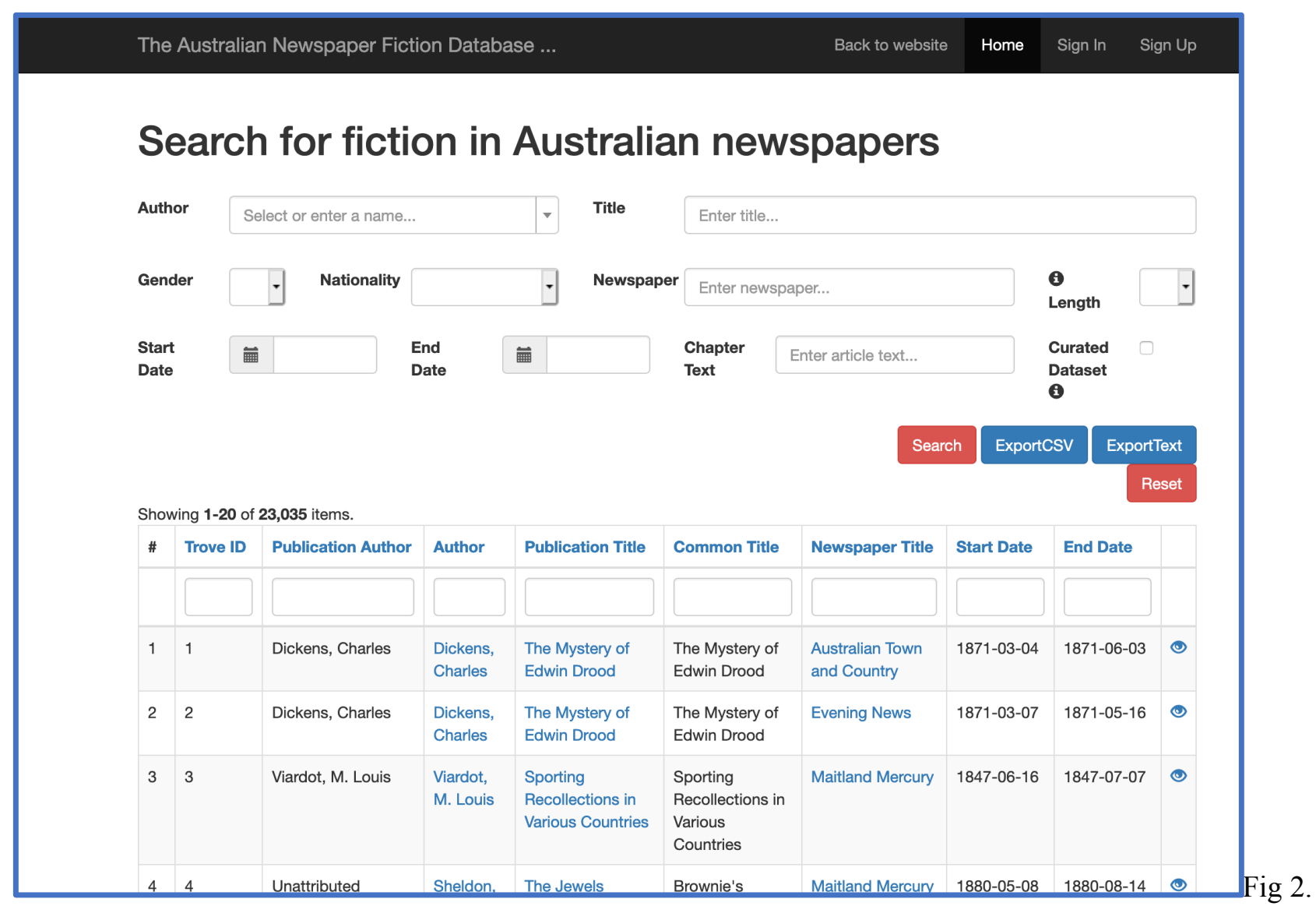

Fig 2. Search page of To Be continued database

One mode of productive reading might be to engage with the formal features of these postdigital literary objects. For instance, as shown in Figure 2, To be continued includes a number of facets for exploring newspaper fiction, including browsing, selecting by the gender or nationality of authors, searching for keywords in the titles or text of the stories, or limiting or ordering by date of publication. As well as familiarising students with important practices for negotiating the prominent digital infrastructure of the database, these functions allow them to shape literary inquiries to their own interests and experiences. For instance, they might use the "newspaper title" facet to find fiction that was published in the place they live or employ keyword searching to discover references to conditions, such as drought, that they have experienced. The stories of the past can thus be collated by students in ways that have a direct relevance to their own stories.

A productive reading also engages with the material features of the postdigital literary object. In To be continued students and teachers can view digitised stories in the context of the newspaper pages by clicking on embedded links to the National Library of Australia's digitised collection (see the screenshot in Figure 3, below). Exploring the material contexts in which these stories were originally published and read provides clues - for instance, from the placement of literature within the whole newspaper and on the 
individual page, the space it occupies, and the materials that frame it - about how these printed texts were produced and what fiction meant for readers in the past. Such multi-literate historical understanding is inhibited when texts are only engaged with as books and is quite different from what is enabled when teachers mediate or direct students to predetermined, curated texts to contextualise their readings.

The stories that can be encountered through large databases are, in many cases, unavailable in printed form or, at the very least, would have previously been very difficult for students and teachers to access. The opportunity to explore a much wider range of fiction can thus enable students to question received (canonical and national) ideas about past literatures. Some of these stories, for instance, present European settlement in Australia as an invasion of Aboriginal land (Bode 2018), while others are radical in their advocacy of women's rights and new approaches to marriage, as in the short story captured in Figure 3, by South Australian writer Catherine Helen Spence.

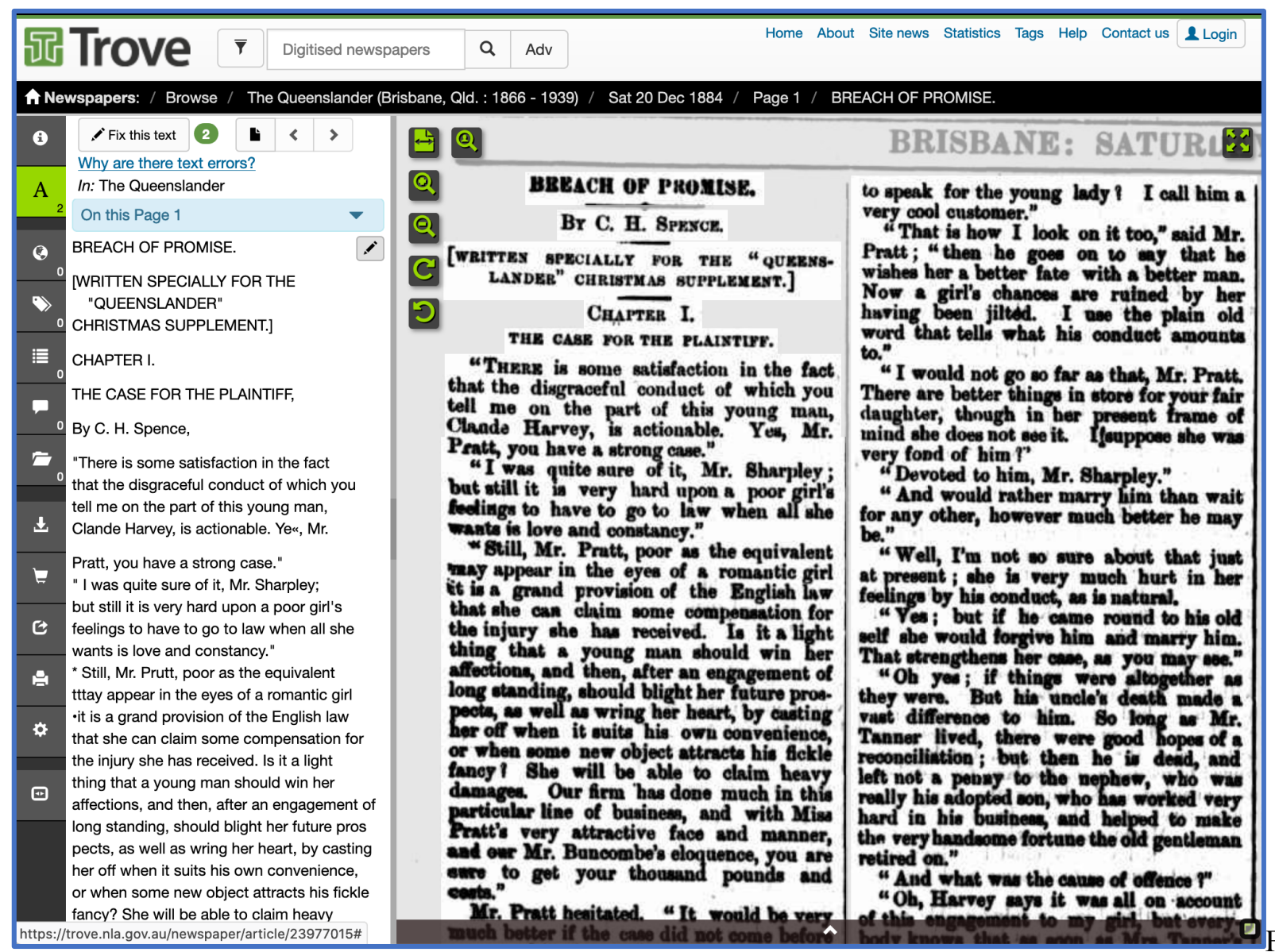

Fig 3. Image of Newspaper Page featuring Spence, 'Breach of Promise' and accompanying OCR derived correctable text from TROVE database National Library of Australia https://trove.nla.gov.au/newspaper)

As well as connecting literature from the past to the personal interests and lived experiences of students, productive reading practices draw connections between the processes that organise their out-ofschool textual worlds and literary textuality in their classroom. To be continued, like other databases, presents opportunities to consider how texts are produced as technical or technological artefacts. Remediated or digitised texts complicate standard divisions of print and digital culture, meaning that readers explore not a printed text or a digitised text but a digital performance of a printed document. This performance involves the translation or re-mediation of a printed page into a digital image, which becomes digital text that is stored in a database accessible, using search algorithms, through a digital interface. Understanding these processes is fundamentally important to understanding the nature of the resulting text. It helps to explain, for instance, why the digital text provided by the database often contains errors: because it is reliant on the capacity of a computer to use Optical Character Recognition to connect a shape derived from a digital scan of an often-damaged printed page to a letter. This is in contrast to contemporary texts (such as a Facebook post) which are created through different processes. Recognising that computer systems and 
architectures shape the terms in which meaning can be presented is an essential literacy skill for the 21 st century.

\section{Distant reading}

As illustrated by the above examples, productive postdigital readings enable students to undertake inquiries that draw together questions of textuality, historicity, materiality, technology, nationality and canonicity. However, postdigital literary literacies do not end with searching a database and reading, or even with investigating the material and technical features of the resulting documents. Postdigital literary literacy also encompasses the use of digital tools to produce new textual (and postdigital literary) objects through "distant reading" practices that further expand literary inquiry beyond a small group of texts.

We focus here on topic modeling, a machine-learning method for identifying latent semantic patterns in the occurrence of words across a large corpus. These patterns are "latent" because they are not apparent before the application of the computer algorithm, and they relate to the likelihood or probability of words occurring together in the same document: this co-occurrence of words is referred to as a "topic". The user or "distant reader" proposes the number of topics for the computer to generate. In Ted Underwood's words, topic modeling then proceeds as "a way of extrapolating backward from a collection of documents to infer the ... 'topics' ... that could have generated them". Topic modeling is often used to explore patterns in word use across documents in very large corpora: such as millions of websites, thousands of scientific abstracts or all of the texts in newspapers across a given period (e.g. Newman and Bloc 2006; Hong and Davison 2010). Providing opportunities for students to create computational models is useful because these artefacts are now key rhetorical devices within contemporary society. Whether the model is a map or a chart or a word cloud, these objects are part of the discourse of culture today and understanding how they are produced and the differences between them is an essential skill.

\begin{tabular}{|c|c|c|c|c|c|}
\hline Rus 5o heratisns Iterations: 700 & \multicolumn{5}{|c|}{ Train with -10 topics } \\
\hline $\begin{array}{l}\text { [0] sir old children link } \\
\text { clerk lie salary hear } \\
\text { began tihe }\end{array}$ & Topic Documents & Topic Correlations & Time Series & Vocabulary & Downloads \\
\hline $\begin{array}{l}\text { [1] money answered john } \\
\text { gen comes father's clarice } \\
\text { muriel gray play }\end{array}$ & \multicolumn{3}{|c|}{$\begin{array}{l}\text { Documents are sorted by their proportion of the } \\
\text { currently selected topic, biased to prefer longer } \\
\text { documents. }\end{array}$} & $\begin{array}{l}\text { Ollection: } \\
\text { mie- Netion } 11.6 \\
\text { step words nen: }\end{array}$ & \\
\hline $\begin{array}{l}\text { [3] old know mother looked } \\
\text { years speak ing ago age } \\
\text { friends }\end{array}$ & \multicolumn{5}{|c|}{$\begin{array}{l}\text { [o/20\%] 1,Down in the World, 'Down in the World Chapter I Down } \\
\text { in the World., [By FLORfENCID WARDEN)] ? ? CIHAPTERr'. L. Everybody ktnowi llow' high staids the relutlation of } \\
\text { lliat eminelet firm of solicitors, leasles. Link and Pbogeon.- Everybody ftlios, too, that oldMr.. Linkhas now been deain } \\
\text { nearly a ... }\end{array}$} \\
\hline $\begin{array}{l}\text { [4] day life way away felt like } \\
\text { saw tell home mabel } \\
\text { [5] ella man child herself }\end{array}$ & \multicolumn{5}{|c|}{$\begin{array}{l}{[3 / 1.256] \text { 6, How I Pawned,A few years ago there was not a railway station within a hundred milles of Hamllington. But }} \\
\text { we had a daily mail from Melbourne, which was delivered at } 7 \text { p.m, when the coach arrived at the fixed time. In winter, } \\
\text { however, this was very seldom, and the safeety-valve which was thus afforde... }\end{array}$} \\
\hline $\begin{array}{l}\text { [6] tho did went aud thought } \\
\text { sho wife husband brown } \\
\text { notice }\end{array}$ & \multicolumn{5}{|c|}{$\begin{array}{l}\text { [2/0.84\%] 5,For Mab, You are not a bit altered, Sara, since I saw you last-nor Mabel neither, for that matter. As far as } \\
\text { yon are concerned a am glad of it; you were always sensible and serious, and yon are keeping your good looks } \\
\text { surprisingly. No one would believe that yon were close upon thirty to look ar y... }\end{array}$} \\
\hline $\begin{array}{l}\text { [7] time mrs good young just } \\
\text { come came long girl poor } \\
\text { [8] miss room going woman } \\
\text { dear ill round hands care like }\end{array}$ & \multicolumn{5}{|c|}{$\begin{array}{l}\text { [7/0.66\%] 10,Breach of Promise, "There is some satisfaction in the fact that the disgraceful conduct of which you tell me } \\
\text { on the part of this young man, Clande Harvey, is actionable. Yee, Mr. Prats, you have a strong case., "I was quite sure of } \\
\text { it, Mr. Sharpley; but still it is very hard upon a poor girl's f... }\end{array}$} \\
\hline $\begin{array}{l}\text { [9] little say did make yes } \\
\text { myself father quite know love }\end{array}$ & \multicolumn{5}{|c|}{ 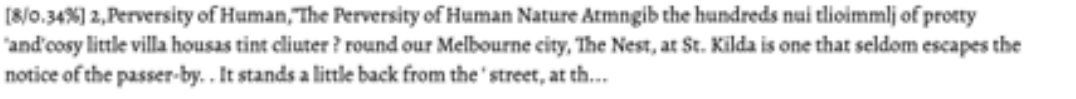 } \\
\hline & \multicolumn{5}{|c|}{$\begin{array}{l}{[4 / 0.25 \times 1] \text { 7,Bebie, TT was summer-time, and unusually hot even for that season. At the close of one of the very hottest }} \\
\text { days, a lady, half-sitting balf-reclining on a couch, fanned herself indolently. Her firmly-marked handsome face-calm, } \\
\text { pale, aud proud-expressed at the moment strong ennui; and the book she ... }\end{array}$} \\
\hline
\end{tabular}

Image of single iteration of a Topic Search of selections of 11 stories (Appendix 1), using David Mimno's jsLDA:In Browser Topic Modeling https://mimno.infosci.cornell.edu/jsLDA/) 
To illustrate how "distant reading" might be enacted, we exported 11 short stories from the To be continued database, all by Australian women (listed in Appendix 1). Our selection was motivated by previous research by the authors which has shown that Australian literature, and women's literature, is often marginalised in the school curriculum (McLean Davies, Martin, Buzacott 2017). These stories were published primarily in Christmas issues of Australian newspapers between 1880 and 1900 - the preFederation boom period in colonial Australian writing.

To produce the above 10-topic model, we uploaded two files to produce the $j s L D A$ topic modeling interface shown in Figure 4. The first was a curated dataset of the first 6,000 words of each of the 11 short stories by Australian women extracted from To be continued. Second, we uploaded a stopword file, which lists words to be excluded from the topic model, including high frequency words such as conjunctions (and, $b u t)$ and articles (the, an) as well as some additional words relevant to the particular stories discussed below. In the $j S L D A$ interface, the number of topics can be adjusted using the sliding bar at the top right hand of the figure; students would ideally experiment with the number of topics, select the texts to use and devise the stopword list to explore the collection. Topic modeling is a good technique for showing students that the supposed "objective" outputs of computational analyses can be contingent. As topic modeling is a probabilistic method, the words contained within each topic will change, sometimes subtly, sometimes considerably, by re-running the model, and as the user "trains" and "tests" probabilities. Rather than a "bug", this aspect of topic modeling is a feature, in that it can enable a discussion of probability and the faith often invested in computational models as objective truth in contemporary society. Variations that are possible in creating the topic model - including the number of iterations and number of topics used, and the contents of the stopword list - can help students and teachers to reflect on how probability works in relation to language to produce patterns.

A "distant reading" facilitates the interpretation as well as the production of new texts. Previous work with teachers by McLean Davies and Martin has shown that, although Australian literature is a compulsory part of the Australian secondary English curriculum (ACARA, 2016), teachers are reluctant to present their students with 19th-century literature due to the perceived archaic language or concepts (McLean Davies, Martin and Buzacott, 2017). In breaking the language in the stories down into "topics" or clusters of words the model produced by this method provides a different way of engaging students with the types of language used in 19th-century fiction, and the focus or genre of these stories. Students might explore the language used in these stories by providing titles or labels for the different topics, such as topic 7: time, Mrs, good young, just, come, came long, girl. By clicking on the topic correlations button, students can see which topics are most likely to occur together. This could lead to a discussion of why particular word clusters might be thematically linked and what this suggests about the character of $19^{\text {th }}$ century Australian women's fiction. Alternatively, clicking on the vocabulary button on the upper right of the $j s L D A$ interface shows a word frequency list, which further assists in developing an understanding of the texts. In this case, there is a high frequency of vocabulary relating to families and homes; this could lead a discussion of domestic realism as a prominent genre in $19^{\text {th }}$ century Australian women's writing. In these different ways, interpreting the topic model presents students with a shifting but evocative picture of the literary language, associations and potential preoccupations of $19^{\text {th }}$ century fiction.

Another form of engagement with the language of the topic model is possible through adjusting the language included. Readers can edit the stopword list and re-run the topic model to see how the word associations change. In the stopword list used in the above topic model, "Mr", "Mrs", and "Miss" had not been removed, which is commonly done. This makes evident the hierarchies of gender common in the 19th century. By reading both the topic model and the stopword list as new texts, students encounter the rich varieties of meaning generation manifested in postdigital literary objects.

\section{Code switching}

Code switching, the final practice we include in this discussion of postdigital literary literacy, involves readers using the model to ask questions about the fiction and using the fiction to ask questions about the model. The power of this approach arises from the different logics used to associate words by humans and computers. In this sense, although the results of the above method are called "topics" there is a lot of debate in the literature about the nature of this "model of language" (Rhody 2012: np) and whether and, if so, how these statistical arrangements of words relate to the concepts used to understand the relationship between literary works (e.g. Buurma 2015; Goldstone \& Underwood 2014). In the classroom, a comparison of the outcomes of this modeling approach - which involves multiple cycles sorting for probabilistic associations 
of words - could enable a discussion of the nature of human interpretation or reading as itself a sorting and meaning-generating system, and also the non-textual data humans bring to managing text.

As a possible code-switching exercise, students could reflect on what is meant by "literary theme" in relation to the words in a particular topic. Selecting topic 0 - as has been done in Figure 4 - rearranges the texts in the middle panel to show which ones have the highest proportions of words in that topic. Students could then hypothesise how the words in topic 0 - money, answered, John, gen, comes, father's, Clarice, Muriel, gray, play - are arranged in the narratives and test their assumptions by reading the stories. Students might write their own narratives set in a contemporary context, using the words in a particular topic and compare their use of the language to the approach taken by the $19^{\text {th }}$ century authors. For secondary teachers, introducing these methodologies to the classroom offers a number of opportunities to encourage critical and questioning approaches to unfamiliar texts. In particular, code switching might assist students to: find a way into and engage with a range of sometimes complex texts; reinforce the role of human interpretation in all textual-meaning making activities and develop new critical digital literary literacy practices that enable a robust generative engagement with these literary works.

\section{Conclusion: Expanding models of English for the 21st century}

We started this article by asserting that the teaching of literature, while remaining central to subject English, has not remained fixed. It has, instead, been responsive to changing definitions of the literary, influenced particularly by the introduction of born-digital texts into the curriculum since the 1980s, and the transformation in theory and practice that the arrival of digital texts produced. We are now at another watershed moment. In this case, the impetus for rethinking and evolving our approach to literary study in subject English comes from the field of the digital humanities, which has broadened the scope of literary study beyond the individual work, or beyond small groups of texts assembled by a teacher. Just as borndigital texts, understood as literary works, required teachers to expand their repertoire of literate practices, massive literary databases require expanded understandings of what might constitute a "literary literacy" for the $21^{\text {st }}$ century, and how to articulate and share these practices with students. As we have discussed, these new literate practices can be expressed in terms of the paradigm of the postdigital, and include productive reading, distant reading, and textual code-switching.

Given its move away from the primacy of the individual text, the question may be raised as to whether what we are proposing is still recognisably English. Subject English is often referred to in terms of "models" such as those articulated by Cox: personal growth; cross curricular; adult needs; cultural heritage and cultural analysis (DESWO, 1989). It is possible to claim that postdigital literary literacy is offering a further model for subject English, one which builds on and extends teachers' expertise, reflecting the digital and digitised modes of the 21 st century. At the same time, this new model draws on, engages critically with, and advances, the previous models. Postdigital literary literacy, as we have described it here, can be seen as addressing contemporary understandings of "adult needs" and "cultural analysis" which are central to communication outside the classroom. These modes of communication, apparent in Web 2.0 and in particular social media platforms, involve curating, assessing, and creating multiple texts, and critically comprehending the ways in which texts are produced in these digitial and digitised environments. With regard to the "cross-curricular" model, the applications we have discussed here cross subject boundaries and re-define possibilities for "subject literacies" (consider the possible applications in History, for example). Literary "heritages" can also be interrogated in new ways that go beyond individual, or small collections of, texts, just as aspects of culture can be read through quite different language-related lenses. Finally, "growth' can encompass new understandings of language and textuality from those dependent on bringing individual experience to an interaction with just the individual text.

In practice, of course, no model of English necessarily displaces any other. In the teaching of reading, the "four resources" model (Freebody \& Luke, 1990) brings together different models with quite different functions and aims (viz. text decoder, text participant, text user and text analyst). Similarly, the 3-D model of literacy (Green \& Beavis, 2014) presents literacy practice as bringing together the different functions of "operational," "cultural" and "critical" literacies. Howie's (2005) transformative model does the same with programming units of work in subject English itself, taking into account each of the approaches he calls "subjective", "structural", "cultural" and "critical". Thus, the practices of English more often than not enact what Locke has termed English teachers" "principled eclecticism" (Locke 2015), involving multiple and varied models (to the extent that practice can be represented as models) of the subject playing out concurrently (Goodwyn 2008). 
Will students benefit from such an approach to English? Will it deal with questions of engagement? Such questions need to be tested empirically, which is the next step in our research. It is our hope that this model will bring a strong sense of agency to the classroom experience, as it enables students to search out the answers to any question they set themselves about experiences, themes, questions of authorship, histories, ideologies and so on. It can also be envisaged as bringing, for example, a digitised version of problem-based learning to the English classroom, an experience that can fit readily with both cultural heritage and cultural analysis approaches to the subject. There are, however, issues with equity and with the "digital divide": schools and students well-resourced in terms of digital technology will be advantaged over those which aren't. This problem of equitable provision needs urgent policy attention on a range of fronts and has been starkly highlighted by the COVID-19 crisis. We can only say here that our approach doesn't seem to compound the problem.

As with all new models and approaches taken in school English, which reflect the expanding purposes of communication and means of engaging with literary texts, in digitally re-mediated culture it will be important for English teachers to take agency and become "their own experts" (Yandell 2019). It will be through a willingness to lead students to new modes of investigation that the possibilities for a "postdigital literary literacy" will be explored and refined. 


\section{REFERENCES}

Abblitt, S. (2019). 'A postdigital paradigm in literary studies', Higher Education Research \& Development, 38:1, 97-109, DOI: 10.1080/07294360.2018.1541313

Australian Curriculum Assessment and Reporting Authority (ACARA). (2016). The Australian Curriculum v8.2. Retrieved from http://www.australiancurriculum.edu.au/english/structure

Beavis, C. (1998). 'Computer games, culture and curriculum', in I. Snyder (ed) Page to Screen: Taking Literacy into the Electronic Era, London: Routledge: 234-255.

Beavis, C. (2013). 'Literary, English and the challenge of multimodality', Changing English, 20:3, 241-252, DOI: $10.1080 / 1358684 X .2013 .816527$

Bode, K (2018). A World of Fiction: Digital Collections and the Future of Literary History. Ann Arbor: Michigan University Press.

Bode, K. \& Hetherington, C. (2018-). To be continued: The Australian Newspaper Fiction Database. https://cdhrdatasys.anu.edu.au/tobecontinued/

Buckingham, D. \& Burn, A. (2007). 'Game literacy in theory and practice', Journal of Educational Media and Multimedia, 16 (3): 323-349.

Bullock, B. \& Toribio, A.J. (eds) (2009). The Cambridge Handbook of Linguistic Code-Switching, Cambridge: Cambridge University Press.

Buurma, R. S. (2015). "The fictionality of topic modeling: Machine reading Anthony Trollope's Barsetshire Series." Big Data \& Society (July-December): 1-6.

Christie, F. \& Derewianka, B. (2008). School discourse: Learning to write across the years of schooling. London: Continuum.

Cope, B. \& Kalantzis, M. (eds) (2000). Multiliteracies: Literacy learning and the design of social futures. London: Routledge.

Cowdy, C. (2016). 'Pedagogical encounters with Inanimate Alice: Digital mobility, transmedia storytelling, and transnational experiences', Jeunesse: Young People, Texts, Cultures, 8 (1): 154-179

Crane, G. (ed) (nd) Perseus Digital Library, Tufts University, http://www.perseus.tufts.edu/.

Da, N. Z. (2019). 'The computational case against computational literary criticism,' Critical Inquiry 45: 601639.

Darling-Hammond, L. 2000, 'Teacher quality and student achievement', Education Policy Analysis Archives, 14, (1): 162-183.

Darling-Hammond, L. 2007, Recognizing and enhancing teacher effectiveness: A policymaker's guide. Washington, DC: Council of Chief State Schools Officers.

Darling-Hammond, L., \& Bransford, J. (2005). Preparing Teachers for a Changing World: What Teachers Should Learn and be Able To Do, San Francisco : John Wiley \& Sons.

Department of Education and Science and the Welsh Office (DESWO) (1989) The Cox Report: English for Ages 5 to 16. London: Her Majesty's Stationery Office.

Doecke, B., Auld, G. \& Wells, M.(eds) (2014) Becoming a Teacher of Language and Literacy, Port Melbourne: Cambridge University Press.

Durrant, C. (2004). English Teaching: Profession or Predicament? English in Australia. 141. 6-8.

Durrant, C., \& Beavis, C.(eds) (2001) P(ICT)ures of English: Teachers, Learners and Technology, Kent Town: Wakefield Press.

Enow, L.\& Goodwyn, A. (2018) 'The invisible plan: how English teachers develop their expertise and the special place of adapting the skills of lesson planning', English in Education, 52 (2): 120-134.

Flanders, J. (dir) (nd). Women Writers Project. Northeastern University, 1999-2016, http://www.wwp.northeastern.edu.

Freebody, P. and Luke, A. (1990) “'Literacies" programs: Debates and demands in cultural context', Prospect, 5: 7-16.

Gee, J. (2003) What Video Games Have to Teach Us About Learning and Literacy, New York: Palgrave.

Glazener, N. (2015). Literature in the Making: A History of U.S. Literary Culture in the Long Nineteenth Century. London: Oxford University Press.

Goe, L.G. 2007, 'The link between teacher quality and student outcomes: A research synthesis', Washington: National Comprehensive Center for Teacher Quality.

Goldstone, A. \& Underwood, T. (2014). "The quiet transformations of literary studies: What thirteen thousand scholars Could Tell Us." New Literary History 45:3, 359-384. 
Goodson, I., \& Medway, P. (1990) 'Introduction'. Bringing English to Order: The History and Politics of a School Subject, London: Falmer.

Goodwyn, A. (2010) The Expert Teacher of English, London and New York: Routledge.

Goodwyn, A. (2012) The status of literature: English teaching and the condition of literature teaching in schools, English in Education, 46:3, 212-227, DOI: 10.111 1/j.1754-8845.2012.01121.

Goodwyn, A. (2008). "English Teachers and the Cox Models." English in Education 26: 4-10. https://doi.org/10.1111/j.1754-8845.1992.tb01074.x.

Green, B. (2002). 'A literacy project of our own?' English in Australia, 134, July: 25-32.

Green, B. (2008) 'English, literacy, rhetoric: Changing the project?' English in Education. 40(1): 7-19.

Green, B. \& Beavis, C. (eds) (2014) Literacy in 3-D: An Integrated Perspective in Theory and Practice, Camberwell: ACER Press.

HathiTrust. https://www.hathitrust.org/

Hayles, N.K. (2004) "Print Is Flat, Code Is Deep: The Importance of Media-Specific Analysis" Poetics Today 25(1): 67-90.

Hattie, J. (2003) “Teachers Make a Difference, What Is the Research Evidence?", Paper presented at the Australian Council for Educational Research Conference.

Hong, L. \& Davison, B. D. (2010). 'Empirical Study of Topic Modeling in Twitter.' $1^{\text {st }}$ Workshop on Social Media Analytics (SOMA '10), July 25, Washington, DC: http://snap.stanford.edu/soma2010/papers/soma2010_12.pdf

Howie, M. (2005) 'A transformative model for programming 7-10 English', English in Australia, 142, pp. 57-63.

Jockers, M. (2013). Macroanalysis: Digital Methods and Literary History. Urbana-Champaign, Ill.: University of Illinois Press.

Lankshear, C. \& Knobel, M. (eds.) (2008) Digital Literacies: Concepts, Policies and Practices. New York: Peter Lang.

Locke, T. (2015). 'Paradigms of English' in Eds. Brindley, S.and Marshall, B. MasterClass in English Education: Transforming Teaching and Learning. MasterClass Series. Bloomsbury Academic. pp.1827.

Manovich, L. (2016). 'The science of culture? Social computing, digital humanities and cultural analytics,' Journal of Cultural Analytics (23 May).

Manuel, J., \& Carter, D. (2016). Sustaining hope and possibility: Early-career English teachers' perspectives on their first years of teaching. English in Australia, 51, 91-103.

McCallum, A. (2012) Creativity and Learning in Secondary English: Teaching for a Creative Classroom, London \& New York: Routledge.

McGann, J. (ed) (nd). Rosetti Archive, http://www.rossettiarchive.org/.

McLean Davies, L, Buzacott, L \& Martin SK, (2019) 'Growing the Nation: the influence of Dartmouth on the Teaching of Literature in Subject English in Australia' in Andrew Goodwyn et al The Future of English Teaching worldwide: Celebrating 50 years from the Dartmouth Conference. Ed. NY: Routledge,: 146-158.

McLean Davies, L., Martin, S.K., Buzacott, L. (2017) Worldly Reading: Teaching Australian literature in the twenty-first century. English in Australia. 52 (3). 21-30.

McLean Davies, L. \& Sawyer, W. (2020) 'On being "well read'”, in B. Marshall, J. Manuel, D. L. Pasternak \& J. Rowsell (eds) The Bloomsbury Handbook of Reading Perspectives and Practices, London: Bloomsbury.

McLean Davies, L., Yates, L., \& Sawyer, W. (forthcoming) 'Literature as knowledge: Investigating the making of English teachers', in International Perspectives on Powerful Knowledge and Epistemic Quality: Implications for Innovation in Teacher Education Policy and Practice, London: Bloomsbury.

Mills, K. (2016) Literacy theories for the digital age. Bristol: Multilingual Matters

Moretti, F. (2013). Distant Reading. London: Verso.

Moretti, F. (2005). Graphs, Maps, Trees: Abstract Models for Literary History. London: Verso.

Moretti, F. (2000). 'Conjectures on World Literature', New Left Review. 1: 54-68.

Muckelbauer, J. (2000). "On Reading Differently: Through Foucault's Resistance.” College English 63, 1: 71-94. https://doi.org/10.2307/379032.

Newman D. J. \& S. Block (2006) 'Probabilistic Topic Decomposition of an Eighteenth-Century American Newspaper' Journal of the American Society for Information Science and Technology, 57, 6: 753-767 
O’ Mara, J. (2019) 'Using digital games in English', in W. Sawyer (ed) Charged with Meaning: Becoming an English Teacher, Seven Hills: Phoenix Education.

Project Gutenberg. https://www.gutenberg.org/

Rhody, L. M. 'Topic modeling and figurative language.' Digital Humanities Quarterly 2:1: http://journalofdigitalhumanities.org/2-1/topic-modeling-and-figurative-language-by-lisa-m-rhody/

Robinson, D.I. 2009, 'Teacher quality as a factor of student achievement: How does the type of teacher certification correlate with student mathematics achievement?'. Paper presented to Phi Delta Kappa International Summit on Quality Educator Recruitment and Retention.

Sawyer, W. (ed) (2019) Charged with Meaning: Becoming an English Teacher, Seven Hills: Phoenix Education.

Shulman, L. (1986). 'Those who understand: Knowledge growth in teaching'. Educational Researcher, 15(2). 4-14.

Underwood, T. "Topic modeling made just simple enough." The Stone and the Shell: Using Large Digital Libraries to Advance Literary History (blog). April 7: https://tedunderwood.com/2012/04/07/topicmodeling-made-just-simple-enough/

Yandell, J. (2019). "English Teachers and Research: Becoming Our Own Experts." Changing English 26, no. 4: 430-41.https://doi.org/10.1080/1358684X.2019.1649087.

Yellowbacks at Emory. https://yellowbacks.digitalscholarship.emory.edu/

Zammit, K., Sinclair, C., Cole, B., Singh, M., Costley, D., Brown a'Court, L., and Rushton, K. 2007, Teaching and Leading for Quality Australian schools: A Review and Synthesis of Research-based Knowledge, Canberra: Teaching Australia. 